\title{
DYNAMIC BALANCE IN CHILDREN: PERFORMANCE COMPARISION BETWEEN TWO TESTING DEVICES
}

${ }^{1}$ Bagley, J., ${ }^{1}$ Boise, S., ${ }^{1}$ Ratamess, N., ${ }^{1}$ Kang, J., ${ }^{1}$ Farrell, A., ${ }^{2}$ Myer, G., ${ }^{1}$ Faigenbaum, A. ${ }^{1}$ The College of New Jersey, Ewing NJ. ${ }^{2}$ Cincinnati Children's Hospital, Cincinnati, OH

joellebagley@yahoo.com, shannboise@yahoo.com, ratamess@tcnj.edu, kang@tcnj.edu, afarrell@tcnj.edu, greg.myer@ccmc.org, faigenba@tcnj.edu

Dynamic balance (DB) refers to the ability to maintain balance while moving and requires strength, flexibility and proprioception. DB is typically measured in youth and adults on a Y-balance kit (YBK). For general use in most public schools, less expensive devices are needed. PURPOSE: To compare DB performance in children measured on a YBK with a less expensive hand-made device (HMD) made from wood slats and cloth measuring tape. METHODS: Sixteen children (age $10.6 \pm 0.3 \mathrm{yr}$; height $146.4 \pm 7.2$ $\mathrm{cm}$, body mass $46.4 \pm 14.9 \mathrm{~kg}$ ) performed the Y balance test using a YBK and a HMD on nonconsecutive days. Standard testing procedures which included 6 warm-up trials and 3 test trials on each leg in the anterior, posteromedial and posterolateral directions were followed. Subjects attempted to maintain single-leg stance while reaching as far as possible in each direction with the contralateral leg. Data were analyzed for each limb in all 3 directions using paired t-tests and Bland-Altman plots. RESULTS: HMD provided a strong relationship to YBK measures with composite correlation coefficients ranging from $\mathrm{r}=0.90$ to $\mathrm{r}=0.94$ and no difference in performance for any direction on either limb between the YBK and the HMD ( $\mathrm{p}>0.05$ ). Bland-Altman plots confirmed no systematic shift in DB performance in any measure between YBK and HMD. CONCLUSION: These findings demonstrate that DB performance on a HMD is comparable to performance on a commercially marketed YBK in children.

Research Funded by American Council on Exercise 